\title{
PANDEMIA E EDUCAÇÃO: AS POLÍTICAS PROMULGADAS NA UNIVERSIDADE FEDERAL DO MATO GROSSO DO SUL
}

\section{PANDEMICS AND EDUCATION: POLICIES PROMOTED AT THE FEDERAL UNIVERSITY OF MATO GROSSO DO SUL}

\author{
Tatiane Lima ${ }^{1 *}$, Joelma Inês Evangelista², Carina Elisabeth Maciel ${ }^{3}$ \\ ${ }^{1}$ Especialista em educação, Universidade Federal de Mato Grosso do Sul, Campo Grande, MS, Brasil, tatianelimaufms@gmail.com \\ ${ }^{2}$ Mestra em educação, Universidade Federal de Mato Grosso do Sul, Campo Grande, MS, Brasil, joelma_ines@hotmail.com \\ ${ }^{3}$ Doutora em educação, Universidade Federal de Mato Grosso do Sul, Campo Grande, MS, Brasil, carina22em@gmail.com \\ *Autora de correspondência
}

\section{Resumo}

O objetivo da pesquisa foi analisar as medidas normativas adotadas pela Universidade Federal de Mato Grosso do Sul (UFMS) de prevenção à disseminação da Covid-19, com foco na permanência e assistência estudantil. Para tanto, foram realizadas buscas de documentos no site da instituição e coleta e análise das produções acadêmicas que dialogam e/ou apresentam dados sobre o contexto pandêmico. Discutem-se, primeiramente, as medidas de prevenção à disseminação da doença, como a suspensão das aulas presenciais e a adoção do Ensino Remoto Emergencial (ERE). Posteriormente, as ações preconizadas na UFMS, em especial na assistência estudantil. A análise das políticas evidencia a necessidade de investimento por parte do Estado. Ademais, apesar da importância das ações adotadas pela instituição, preocupada com o calendário acadêmico e fomentado estratégias para o acesso das/os acadêmicas/os às aulas remotas, entendese, todavia, mais do que cumprir um cronograma pré-estabelecido, compreendemos que a UFMS também precisa investir em ações que considerem a qualidade da educação ofertada, além da intervenção que já vem sendo realizada, sempre considerando as dificuldades de uso e acesso às tecnologias e as condições socioeconômicas e pandêmicas que interferem no processo de ensino e de aprendizagem.

Palavras-chave: Acesso. Educação superior. Pandemia. Políticas.

\begin{abstract}
The objective of the research was to analyze the normative measures adopted by the Federal University of Mato Grosso do Sul (UFMS) to prevent the dissemination of Covid-19, with a focus on permanence and student assistance. For this purpose, document searches were carried out on the institution's website and the collection and analysis of academic productions that dialogue and/or present data on the pandemic context. Firstly, measures to prevent the spread of the disease are discussed, such as the suspension of in-person classes and the adoption of Remote Emergency Education (ERE). Subsequently, the actions recommended at UFMS, especially in student assistance. The analysis of policies highlights the need for investment on the part of the State. Furthermore, despite the importance of the actions taken by the institution, concerned with the academic calendar and promoting strategies for academic access to remote classes, it is understood, however, that more than complying with a pre-established schedule, we understand that UFMS also needs to invest in actions that consider the quality of education offered, in addition to the intervention that has already been carried out, always considering the difficulties in using and accessing technologies and the socioeconomic and pandemic conditions that interfere in the teaching and learning process.
\end{abstract}

Keywords: Access. College education. Pandemic. Policies.

CUNIS-MG. All rights reserved. 


\section{INTRODUÇÃO}

Este estudo tem como objetivo analisar as medidas normativas adotadas pela Universidade Federal de Mato Grosso do Sul (UFMS) de prevenção à disseminação da Covid-19, com foco na permanência e assistência estudantil. Portanto, considerando as políticas, notícias, pesquisas e produções acadêmicas sobre a referida crise sanitária e a educação superior, discutimos acerca das legislações e medidas preconizadas em caráter pandêmico, bem como, destacamos as ações de assistência estudantil implementadas na UFMS, em decurso do Ensino Remoto Emergencial (ERE) em contexto de pandemia.

As atividades educacionais foram suspensas a partir de março de 2020, em virtude das medidas de isolamento anunciadas pelos governos municipais, estaduais e federal, obrigando as Instituições de Ensino Superior (IES) de todo o país a adotarem o ensino remoto, por meio de tecnologias e serviços de comunicação virtuais, a partir das orientações do Conselho Nacional e dos Conselhos Estaduais de Educação. Na UFMS, a partir dos decretos e pareceres do Ministério da Educação (MEC), do Conselho Nacional de Educação (CNE), e seguindo as orientações dos órgãos sanitários, optou-se por suspender as aulas presenciais em março de 2020, mantendo o calendário acadêmico que passaria a ser executado de modo on-line, por meio do ERE.

Para tal, as decisões tomadas foram sancionadas por meio de portarias e resoluções, e foi criado um canal de comunicação (Cf. www.ufms.br/coronavirus), a fim de informar à comunidade acadêmica e à comunidade externa sobre as medidas de prevenção à Covid-19. No que tange ao processo educacional, foi criado um 'Guia das Atividades Acadêmicas durante a Covid-19' (Cf. https://link.ufms.br/guiaCovid19 v1) destinado às/aos professoras/es, técnicas/osadministrativas/os e estudantes de graduação e pós-graduação, e foi desenvolvido um plano de contingência criado para organizar as bases das ações que seriam instituídas pela universidade com "[...] três dimensões interdependentes: 1) Medidas de Cuidados com as Pessoas; 2) Medidas de Atividades Acadêmicas; e 3) Medidas de Comunicação" (UFMS, 2020, p. 6).

Na perspectiva de construir uma análise dessas políticas e ações institucionais, este artigo divide-se em quatro partes. Na primeira apresentamos a fundamentação teórica, em que discutimos sobre as políticas elaboradas para educação superior a partir das medidas de prevenção. $\mathrm{Na}$ segunda parte destacamos a metodologia da pesquisa. Na terceira apresentamos as ações de assistência estudantil implementadas na UFMS para auxiliar as/os acadêmicas/os durante a pandemia, bem como apresentamos os resultados dessas políticas e tecemos discussões. Na quarta parte, por fim, temos as considerações finais.

\section{FUNDAMENTAÇÃO TEÓRICA}

O Brasil foi o primeiro país da América Latina a registrar um caso de Covid-19, com a primeira pessoa infectada e identificada no final de fevereiro de 2020 (RÍOS, 2020). Consequentemente, com o aumento progressivo dos casos, visando conter os índices de contágio e evitar um estado de calamidade no Sistema Único de Saúde (SUS), as medidas de prevenção impostas, tanto pela Organização Mundial da Saúde (OMS) quanto pelo Ministério da Saúde (MS), foram "[...] distanciamento social, etiqueta respiratória e de higienização das mãos, uso de máscaras, limpeza e desinfecção de ambientes, isolamento de casos suspeitos e confirmados e quarentena dos contatos dos casos de covid-19 [...]" (BRASIL, 2020b). 
No contexto educacional, as determinações para orientar as adequações do calendário educacional de 2020 foram promulgadas por meio de portarias normativas publicadas pelo MEC. Em 17 de março de 2020, por meio da Portaria no 343, o MEC autorizou a substituição das aulas presenciais por aulas remotas que utilizassem tecnologias e serviços de comunicação virtuais por 30 dias. Posteriormente, a Portaria no 345, de 19 de março de 2020, e a Portaria no 473, de 12 de maio de 2020, prorrogaram o prazo por mais 30 dias. Por fim, por meio da Portaria no 544, de 16 de junho de 2020, o MEC autorizou a substituição das aulas até o final de 2020, com exceção dos cursos que necessariamente demandam atividades presenciais.

O CNE, por meio do Parecer CNE/CP no 5, de 28 de abril de 2020 e homologado pelo MEC em 01 de junho de 2020, flexibilizou o calendário acadêmico ao desobrigar o cumprimento de 200 dias letivos, assegurado na Medida Provisória no 934, de 01 de abril de 2020, aprovada pelo Congresso Nacional e convertida na Lei no 14.040, de 18 de agosto de 2020. Nesse período, até o dia 15 de julho de 2020, dentre as 69 Universidades Federais, 53 haviam interrompido as aulas de graduação, 10 estavam realizando atividades remotas e 06 universidades realizavam atividades parciais (BRASIL, 2020a).

Portanto, com a pandemia do Covid-19, as IES suspenderam suas atividades educacionais e tiveram que adaptar o ensino, a pesquisa e a extensão por meio do ensino remoto. No entanto, essas mudanças ocorreram de maneiras distintas, de acordo com a natureza pública ou privada da instituição, com os cursos (com disciplinas mais teóricas ou mais práticas) e com o perfil socioeconômico das/os professoras/es e das/os estudantes. Ademais, como o MEC não ofereceu subsídios às diversidades de situações e da dificuldade de acesso às tecnologias/internet, foi delegada a responsabilidade aos estados, municípios e às IES a disponibilização das ferramentas para o acesso às aulas. Como consequência, tais ações acirraram os processos de desigualdades que já estavam em curso (PIRES, 2021).

Referente ao crescimento da renda e da desigualdade no Brasil desde a virada para o século XXI, Barbosa, Souza e Soares (2020) consideram dois ciclos, o primeiro até 2014 caracterizado pelo crescimento da renda e pela diminuição das desigualdades, e o segundo no período de 2015 a 2018, cujas tendências se invertem. Nesse processo, as famílias mais ricas e as famílias mais pobres foram afetadas de formas diferentes. Com base nos dados da Pesquisa Nacional por Amostra de Domicílios Contínua (PNAD Contínua) do período de 2012 a 2018, durante o segundo ciclo os 50\% mais pobres experimentaram crescimento negativo, enquanto os $50 \%$ mais ricos, crescimento positivo.

Além das questões econômicas, as desigualdades educacionais também estavam nesse percurso. Embora o acesso e a permanência na educação superior têm sido historicamente limitados por aspectos socioeconômicos e culturais, como renda familiar, cor/etnia e gênero, durante os governos Lula (2003 a 2010) e Dilma (2011 a 2016/interrompido), políticas e programas foram promulgados com o intuito de equiparar as condições de acesso e permanência a todas/os, sendo amparadas pela Constituição Federal de 1988 (CF) e pela Lei de Diretrizes e Bases da Educação Nacional (LDB), Lei no 9.394/1996.

Foram criados o Programa Universidade para Todos (PROUNI) em 2005, o Programa de Reestruturação e Expansão das Universidades Federais (REUNI) em 2007, a criação do Sistema de Seleção Unificada (SISU) e a reformulação do Exame Nacional do Ensino Médio (ENEM) para o acesso à educação superior em 2009, a ampliação do atendimento pelo Fundo de Financiamento ao Estudante do Ensino Superior (FIES) em 2010, que passou a ter um fluxo contínuo de inscrições e a ter como agente operador o Fundo Nacional de Desenvolvimento da Educação (FNDE), o Programa 
Nacional de Assistência Estudantil (PNAES) em 2010, e a Lei no 12.711, nomeada como Lei de Cotas, aprovada em 2012.

Como a exclusão da maioria da população do acesso aos direitos sociais, incluindo o direito à educação superior, expressava a desigualdade social no Brasil, nos dois mandatos do governo Lula as políticas e programas tiveram como foco a inclusão social. O processo de expansão pela via das IES privadas e privadas-mercantis, iniciado durante o governo Fernando Henrique Cardoso (FHC) (1995 a 2002), teve continuidade por meio do PROUNI e do FIES, enquanto novas IES foram criadas para contemplar a criação das novas vagas e dos programas de acesso e permanência.

Na gestão de Dilma os programas do governo Lula também tiveram continuidade enquanto novas ações foram promulgadas. Em 2012, além da aprovação da Lei de Cotas, o processo de seleção e classificação do SISU passou a implementar as políticas de ações afirmativas, reservando um percentual das vagas também para alunas/os oriundos de escolas públicas, pessoas com deficiência, entre outras especificidades de acordo com as universidades públicas.

No entanto, desde o golpe de 2016, acompanhada pela ruptura democrática, a educação superior têm sido impactada em diferentes aspectos; na infraestrutura física, com a interrupção de obras e deterioração das instalações existentes nas universidades públicas, nas políticas de expansão, acesso e permanência, com o estancamento e desaceleração do movimento de expansão de matrículas e cursos, e no custeio e investimento, com cortes, desregulamentação e ataque aos direitos trabalhistas (MANCEBO, 2018).

Sob essa perspectiva, a pandemia contribuiu para o fortalecimento das desigualdades educacionais. Além das demarcações sócio-históricas que interferem no acesso à educação superior, nesse contexto pandêmico a permanência de determinadas/os estudantes nas universidades também tiveram como obstáculo a dificuldade de acesso à internet e à aparelhos eletrônicos para realização das atividades e participação nas aulas, pois, conforme os dados apresentados pela Pesquisa Nacional de Amostra por Domicílio (PNAD) até 2019 aproximadamente 4,3 milhões de estudantes ainda não tinham acesso à internet (IBGE, 2019).

Segundo a Organização das Nações Unidas para a Educação, a Ciência e a Cultura (Unesco), $87 \%$ da população mundial de estudantes foram afetados pela pandemia, contabilizando 1,5 bilhão de crianças e jovens (UNESCO, 2020). No Brasil, com o intuito de minimizar as lacunas educacionais vigentes, as universidades públicas desenvolveram, então, ações para equiparar as condições de vulnerabilidade das/os estudantes.

\footnotetext{
Após período com as atividades de ensino paralisadas, a maioria das universidades federais iniciou pesquisas para investigar a situação social dos seus alunos e docentes durante a pandemia. Nesse período, a criação de diversos comitês voltados à Covid-19, nas suas várias dimensões, foram instalados pelas universidades para estabelecer medidas de segurança e protocolos para um possível retorno, comitês para acolhimento de estudantes que manifestassem necessidades de assistência, comitês para o desenvolvimento de projetos de combate à pandemia e até de doação de Equipamentos de Proteção Individual (EPI), além da abertura de editais para convocação de interessados em receber computadores e pacote de dados para o acompanhamento das aulas, que começaram a ser programadas para meados de agosto (CASTIONI, 2021, p. 407).
}

Além do acolhimento das/os estudantes que manifestassem necessidades de assistência, as universidades também direcionaram ações para as/os professoras/es e servidoras/es, pois, ainda que as atividades remotas tenham facilitado a participação em bancas, o acesso a conferências, 
palestras e o processo de internacionalização, também alteraram as relações de ensino e aprendizado, incluindo o ritmo, a rotina e a intensidade de trabalho. Nesse segmento, no tópico de resultados apresentaremos as estratégias adotadas na UFMS para atender tanto as/os acadêmicas/os, quanto as professoras/es, as/os servidoras/es e a comunidade externa.

\section{MATERIAIS E MÉTODOS}

Para o desenvolvimento do presente estudo, caracterizado como bibliográfico e documental, de abordagem qualitativa e descritiva, foi realizado, primeiramente, o levantamento e análise das produções acadêmicas que apresentam e discutem o tema proposto. Para tanto, foram consultadas as seguintes bases de dados: Portal de Periódicos CAPES (Coordenação de Aperfeiçoamento de Pessoal de Nível Superior) e IBICT (Instituto Brasileiro de Informação em Ciência e Tecnologia). Ademais, também buscamos as normativas e decretos sancionados pelo MEC no ano de 2020, além dos documentos da UFMS de ações institucionais de enfrentamento à Covid19 e seus benefícios à sociedade publicado em 2020, e o relatório de acompanhamento de ações durante o ERE do primeiro semestre de 2021 na UFMS. Antes de mais, cabe evidenciar que consideramos o conjunto dos documentos publicados e das ações desenvolvidas como parte de uma política de combate à Covid-19.

\section{RESULTADOS E DISCUSSÕES}

A partir dos decretos sancionados pelo MEC que regulamentam a continuidade do ano letivo de modo remoto às instituições educacionais, bem como as orientações do MIS e da OMS sobre como deveriam proceder às ações de prevenção e combate à pandemia, a UFMS passou a desenvolver estratégias que visassem atender as/os professoras/es, as/os acadêmicas/os, as/os servidoras/es, e a comunidade externa.

Assim, neste item discutiremos as ações e estratégias de prevenção e combate a pandemia na UFMS, com ênfase para as políticas voltadas às/aos acadêmicas/os, a fim de garantir o acesso, a permanência e a adaptação à nova forma de ensino emergencial, o ERE. Para tanto, será utilizado como referência os sites criados pela UFMS, que constam informações sobre a pandemia, as reportagens postadas, além do Relatório de ações institucionais de enfrentamento à Covid-19 e seus benefícios para a sociedade, publicado pela UFMS em 2020 e 2021, em decorrência das ações do Comitê Operativo de Emergência (COE), instituído em março de 2020 pela Portaria $n^{\circ} 387$,

[...] com base nas orientações do COE. As aulas e as atividades presenciais foram imediatamente substituídas para evitar mobilidade e aglomeração nos prédios das universidades. Alinhada aos protocolos da Secretaria de Estado da Saúde de MS e do Ministério da Saúde e resguardadas a autonomia e as particularidades das instituições, a UFMS manteve o Calendário Acadêmico de 2020 de acordo com o novo planejamento das atividades de cada Unidade da Administração Setorial (UAS), instituindo o Ensino Remoto de Emergência (ERE) (UFMS, 2020, p. 4).

Dessarte, o ERE foi adotado na UFMS em todos os cursos presenciais de graduação e pósgraduação, que passaram a ser inseridos na plataforma AVA-Moodle, também conhecido como Ambiente Virtual de Aprendizagem - Moodle, já utilizada pela instituição para os cursos que possuem sua matriz curricular voltados para a Educação a Distância (EaD). Todavia, é preciso destacar que ERE e EaD não podem ser associados como sinônimos, 
[...] pois além de ser desenvolvido em contexto de emergência, não pressupõe os elementos legais necessários para a oferta de cursos na modalidade a distância e nem atende as suas características intrínsecas. Ou seja, o Ensino Remoto Emergencial é realizado de forma a adaptar um currículo que foi planejado para ser desenvolvido presencialmente, num contexto com uso de tecnologias diversas, em que professores estão separados espacialmente dos estudantes (única característica em comum com a EaD) por conta do isolamento necessário para a não contaminação pela Covid-19 (LIMA; ALONSO; ECHALAR, 2021, p. 84).

Outras tecnologias de comunicação também foram utilizadas pela universidade. O Google Classroom, o Google Meet, os drives e emails foram ferramentas importantes para as aulas e o envio dos materiais a serem utilizados, além do Whatsapp, que também passou a ser utilizado para promover um contato mais direto entre as/os professoras/es e estudantes sobre a criação de grupos. Ademais, os seminários e as palestras passaram a ser realizadas pelo Youtube, plataforma de compartilhamento de vídeos, com a criação de canais das unidades e cursos da UFMS.

Cabe destacar também acerca do Programa de pós-graduação em Enfermagem do campus da UFMS de Três Lagoas, que publicou uma reportagem destacando as ações pedagógicas utilizadas no curso no decorrer da pandemia,

As tecnologias de ensino a distância frequentemente utilizadas são textos e artigos para estudo, aulas em PowerPoint com áudio explicativo, aulas nas plataformas Google Hangouts, Zoom Video Communications e Google Classroom, produção de textos reflexivos, produção de materiais em grupo, trocas de informações e devolutivas por email, por grupo no WhatsApp e por Google Drive (JUNIOR, 2020).

Esse volume de diferentes estratégias utilizadas pela instituição denotam o caráter de improviso que o ensino remoto teve no território brasileiro, em virtude dos decretos do MEC que não orientaram as unidades educativas sobre como proceder, metodologicamente, para que o ano letivo tivesse continuidade. Embora essas ferramentas adotadas tenham sido essenciais para a continuidade do ensino, não se deve deixar de levar em consideração as dificuldades enfrentadas pelas/os acadêmicas/os em relação ao acesso à tecnologia no Brasil, a falta de um ambiente adequado para a aprendizagem em casa, e às condições psicológicas durante esse período, o que deve levar as universidades a se atentarem para as condições de acesso, permanência e conclusão destas/es estudantes no decorrer desses dois anos emergenciais.

Sendo assim, é significativo destacar as ações da UFMS no que tange às políticas e estratégias fomentadas para que as/os acadêmicas/os conseguissem continuar a ter acesso aos cursos escolhidos. Uma das medidas iniciais tomadas pela entidade foi a publicação de editais, dos quais dois deles se destacam, o edital no 22/2020 -Seleção de Ideias e Projetos de Pesquisa, Extensão e Inovação para o Enfrentamento ao Novo Coronavírus e o no 23/2020 - Cadastro de voluntários da UFMS para auxílio técnico - especializado no enfrentamento ao novo coronavírus, que a posteriori fomentaram outras ações como "[...] editais emergenciais de auxílio alimentação, inclusão digital, uso de laboratórios de informática, Equipamentos de Proteção Individual (EPI), empréstimo de equipamentos tecnológicos [...]" (UFMS, 2020, p. 4).

Os programas de assistência, inclusão e integração estudantil seguem sob a responsabilidade da Pró-Reitoria de Assuntos Estudantis (PROAES) em parceria com a Diretoria de Assuntos Estudantis (DIAES), “[...] responsável pela coordenação, execução, acompanhamento e avaliação da política de assistência estudantil e acompanhamento das ações dirigidas ao estudante em situação de vulnerabilidade socioeconômica" (UFMS, 2021, p. 17), bem como, com a Diretoria 
de Inclusão e Integração Estudantil (DIIEST) que “[...] é a unidade responsável pelo acompanhamento das atividades relativas a estágios, pelo fomento e planejamento de políticas e estratégias para estreitar e articular relacionamentos com a comunidade de estudantes" (UFMS, 2021, p. 16).

Das ações fomentadas diretamente às/aos estudantes, especialmente aquelas/es em condições de vulnerabilidade, descrevemos no quadro 1 as abordagens utilizadas pela UFMS no ano de 2020. Ressaltamos que as ações foram contabilizadas até setembro (mês em que o relatório foi elaborado e publicado), desse modo, posteriormente apresentaremos os dados relativos a 2021 (Quadro 1).

Quadro 1 - Ações fomentadas aos acadêmicos da UFMS em 2020

\begin{tabular}{|c|c|}
\hline POLÍTICAS E AÇÕES & RESULTADOS \\
\hline $\begin{array}{c}\text { Ligações telefônicas e contatos por Whatsapp a } \\
\text { todas/os as/os estudantes que recebem o auxílio } \\
\text { de assistência estudantil }\end{array}$ & 3.994 ligações telefônicas e 1.211 contatos via Whatsapp \\
\hline Atendimento psicológico remoto & $\begin{array}{l}455 \text { estudantes foram atendidas/os de modo remoto até } \\
\text { setembro de } 2020\end{array}$ \\
\hline $\begin{array}{l}\text { Reunião com estudantes de diferentes aldeias } \\
\text { indígenas da região }\end{array}$ & $\begin{array}{l}\text { Parceria com as escolas próximas para o acesso a internet e } \\
\text { documento solicitando a instalação de antenas de internet } \\
\text { nas aldeias }\end{array}$ \\
\hline $\begin{array}{c}\text { Bolsas de extensão para a participação em } \\
\text { projetos de pesquisa de enfrentamento e } \\
\text { combate à COVID-19 com recursos próprio no } \\
\text { valor de } \mathrm{R} \$ 400,00\end{array}$ & $\begin{array}{c}\text { Investimento de } \mathrm{R} \$ 140.000,00 \text { e mais de } \mathrm{R} \$ 26.600,00 \text { para } \\
\text { despesas }\end{array}$ \\
\hline $\begin{array}{l}\text { Editais destinados ao fomento de auxílio às/aos } \\
\text { estudantes no intuito de promover a } \\
\text { permanência dos mesmos no curso }\end{array}$ & $\begin{array}{l}\text { Edital para uso dos laboratórios de informática em todos } \\
\text { campus e Cidade Universitária; Edital para concessão de } \\
\text { auxílio inclusão digital - acesso à internet; Edital para } \\
\text { concessão de auxílio para aquisição de Equipamentos de } \\
\text { Proteção Individual; Cadastro para empréstimo de } \\
\text { equipamento tecnológico; Edital para concessão de auxílio } \\
\text { alimentação emergencial para estudantes matriculadas/os } \\
\text { em campus onde há restaurantes universitários }\end{array}$ \\
\hline
\end{tabular}

Fonte: UFMS, 2020.

Como as ações planejadas em 2020 foram promulgadas em caráter emergencial, as ligações, outras formas de contato, e os editais de projetos promulgados pela instituição tinham como características mapear e promulgar as políticas que viessem a contribuir para a permanência e corroborar para o combate à pandemia. Assim, os resultados expostos no quadro são iniciais, uma vez que o relatório de ações institucionais da UFMS não apresentou os dados relativos aos resultados obtidos com os editais. Neste aspecto, os dados oriundos do relatório de 2021 seguem mais completos, visto que são resultados mais amplos das ações sancionadas em 2020.

O Relatório de Acompanhamento de Ações Durante o Ensino Remoto de Emergência foi atualizado em julho de 2021, sendo a compilação dos resultados das políticas acadêmicas implementadas na instituição. Antes da pandemia, a UFMS já contava com as seguintes políticas de 
auxílio: creche, permanência, moradia, alimentação, apoio à/ao estudante com deficiência, e Bolsa Permanência do MEC (BPMEC), que continuaram atendendo as demandas solicitadas no decorrer da pandemia, e apresentaram como resultados os atendimentos dispostos no Quadro 2.

Quadro 2 - Quantitativo de auxílio PNAES - 2021.1

\begin{tabular}{|c|c|c|c|c|c|c|}
\hline AUXÍLIO & JANEIRO & FEVEREIRO & MARÇO & ABRIL & MAIO & JUNHO \\
\hline Permanência & 1716 & 1657 & 1645 & 1621 & 1614 & 1611 \\
\hline Creche & 0 & 47 & 47 & 46 & 46 & 46 \\
\hline Moradia & 617 & 612 & 608 & 599 & 596 & 591 \\
\hline Alimentação & 310 & 308 & 1013 & 990 & 985 & 983 \\
\hline $\begin{array}{l}\text { Apoio à/ao estudante com } \\
\text { deficiência }\end{array}$ & 0 & 0 & 0 & 11 & 11 & 11 \\
\hline BPMEC & 303 & 261 & 262 & 256 & 256 & 256 \\
\hline
\end{tabular}

Fonte: UFMS, 2021.

O Quadro 2 evidencia resultados significativos e teceremos algumas considerações e correlações a respeito. $O$ auxílio de permanência apresenta uma certa variação, todavia, não muito discrepante, e é auxílio o que mais atende às/aos estudantes, o auxílio creche passa a ser utilizado a partir de fevereiro e se mantém estável, e o auxílio moradia apresenta considerável número de estudantes atendidas/os. O auxílio alimentação se destaca apresentando a maior mudança nas solicitações, em janeiro 310 estudantes foram beneficiadas/os, em março deu um salto para 1013 auxílios e se manteve alto nos meses seguintes. Já o apoio à/ao estudante com deficiência passou a ser solicitado apenas a partir de abril para 11 estudantes, sem apresentar modificações nos meses seguintes. Por fim, a BPMEC, concedida a 303 estudantes, diminuiu no decorrer dos meses.

É possível identificar a partir do Quadro 1 que os auxílios que possuem mais solicitação são: a bolsa permanência, o auxílio moradia e o auxílio alimentação. Esses auxílios seguem diretamente ligados às condições socioeconômicas e à variação no acesso de alguns, como o auxílio alimentação, que pode ser resultado da alta inflacionária dos preços no supermercado, bem como o elevado número de desemprego que assolou as/os brasileiras/os nesse contexto pandêmico. De acordo com o IBGE (2021), no terceiro trimestre de 2021 foram consideradas desempregadas 13,5 milhões de pessoas, a taxa de desemprego nesse mesmo período corresponde a $12,6 \%$ da população brasileira.

Para garantir a permanência das/os estudantes e as demandas do ensino remoto foram implementadas cinco novas modalidades de auxílio: Auxílio Alimentação Emergencial (onde há restaurante universitário) que beneficiou 689 acadêmicas/os; Disponibilização de laboratórios de informática (presencial para todos dentro das medidas de segurança e proteção à COVID-19); Fornecimento de EPIs via editais solicitados por 11 estudantes; Chromebooks e notebooks, fomentados a 514 estudantes; Chips de dados 20Gb/mês em parceria com o programa Alunos Conectados do MEC, em que 915 estudantes foram atendidas/os (UFMS, 2021).

No relatório anterior foi identificado a dificuldade das/os estudantes indígenas com relação ao acesso à internet, nesse aspecto, foi promovido no Campus de Aquidauana (CPAQ) o programa 
Aldeias Conectadas, que se constitui como um plano piloto, mas que tem corroborado para o acesso desse grupo as aulas remotas na região. Segundo a UFMS (2021), esse programa abrange o total de sete aldeias inicialmente, cujas aldeias foram escolhidas tendo como critério residirem nelas ao mínimo dez acadêmicas/os indígenas. Das ações realizadas no CPAQ,

Instalação de radiotransmissores (internet via rádio);Recursos próprios da UFMS e MEC; Em busca permanente por parcerias e apoio do MEC e do Governo do Estado de Mato Grosso do Sul para a expansão do serviço para as demais aldeias em que a UFMS tem estudantes;Foram instalados 2 (dois) pontos de acesso (Access Points) de sinal Wi-fi por local escolhido (escola/centro);2 (duas) torres de comunicação para radiotransmissores;Disponível 24 Horas por dia / 7 dias por semana;Capacidade de 20 Mbps;Terceirização de infraestrutura de TIC: A contratada responsabiliza-se por manutenções e correções de falhas; Prazo contratual de 48 meses: Vigência: 01/03/2021 a 28/02/2025; Valor/mês: R\$ 14.000,00, R\$2.000,00/aldeia (Total: R\$672.000,00 - 4 anos);Empresa prestadora do serviço (licitação realizada) - Contrato no 186/2020UFMS:Netware Brasil Telecomunicações;Monitoramento dos Serviços: CPAQ e Agetic (UFMS, 2021, p. 20).

O CPAQ conta com 500 estudantes indígenas, correspondendo a 1/3 (um terço) das/os estudantes do campus, desse modo, as ações feitas em parceria com os recursos oriundos da UFMS e MEC têm contribuído para o combate à pandemia, visto que não é preciso se deslocar da aldeia para ter acesso às aulas, elemento que pode e pode colaborar também para permanência das/os estudantes indígenas no curso.

$\mathrm{O}$ atendimento psicológico em contexto de pandemia também deve ser entendido como uma estratégia de permanência, visto que faz parte das políticas de assistência estudantil, além de contribuir para a minimização de transtornos de ansiedade e ser uma ferramenta que pode contribuir para o combate ao suicídio. Em vista disso, o Relatório de Acompanhamento de Ações Durante o Ensino Remoto de Emergência de 2021 apresentou os resultados acerca dos atendimentos psicológicos no primeiro semestre, conforme Quadro 3.

Quadro 3 - Atendimentos Psicológicos 2021.1

\begin{tabular}{|c|c|c|}
\hline AÇÕES REALIZADAS & ESTRATÉGIAS ADOTADAS & $\begin{array}{c}\text { QUANTIDADE DE } \\
\text { ACADÊMICOS ENVOLVIDOS }\end{array}$ \\
\hline $\begin{array}{c}\text { Atendimento psicológico individual à/ao } \\
\text { estudante (Psicologia) }\end{array}$ & Online & $\begin{array}{c}204 \text { estudantes atendidas/os } \\
780 \text { atendimentos }\end{array}$ \\
\hline Atividades em grupo & Online & Ontudantes estudantes \\
\hline $\begin{array}{c}\text { Oficina 'Vida na Universidade' com o setor } \\
\text { de Psicologia na recepção de calouras/os }\end{array}$ & $\begin{array}{c}\text { Contato com profissionais de } \\
\text { psicologia, orientações para } \\
\text { preencher a solicitação do } \\
\text { atendimento }\end{array}$ & 21 estudantes \\
\hline $\begin{array}{c}\text { Atendimento/acolhimento/ } \\
\text { psicológico da equipe de Psicologia da } \\
\text { UFMS }\end{array}$ & $\begin{array}{c}\text { Plantão e acompanhamento } \\
\text { psicológico, orientação e conduta } \\
\text { educativa online, via Google Meet }\end{array}$ & \\
\hline Atendimento Psicológico & & \\
\hline
\end{tabular}

Fonte: UFMS, 2021. 
De acordo com o Quadro 3, foram realizadas cinco diferentes ações de atendimento psicológico com três tipos de estratégias, cuja quantidade de estudantes que obtiveram acesso a tais ações, representa a relevância desse recurso, bem como sua continuidade no decorrer da pandemia. Ainda no aspecto das políticas de assistência estudantil, também cabe destacar as ações para os atendimentos de serviço social.

As ações fomentadas compreenderam aspectos de: acompanhamento escolar de 32 estudantes, encaminhamento ao serviço de Psicologia da UFMS ou para a Rede Municipal de 54 estudantes, 31 entrevistas realizadas por assistentes sociais, 2.612 atendimentos remotos, 435 atendimentos realizados às/aos estudantes bolsistas, 180 orientações e acolhimentos às/aos novas/os acadêmicas/os, 283 acadêmicas/os foram atendidas/os/orientadas/os sobre o processo de seleção aos auxílios estudantis ofertados pela instituição, 62 atendimentos foram encaminhados para o atendimento psicológico da UFMS e por fim 18 atendimentos foram realizados acerca de diversas dificuldades como: alimentação, moradia, agressão, entre outras (UFMS, 2021).

As estratégias utilizadas pela assistência estudantil da UFMS foram realizadas via: Whatsapp (mensagem de texto e vídeo-chamada), Google meet, emails, telefones, visando garantir os cuidados sanitários, e, ao mesmo tempo, atender, acolher e orientar as/os estudantes dos seus direitos. As ações desenvolvidas pela assistência estudantil constituem-se como políticas que contribuem tanto para a adaptação das/os novas/os acadêmicas/os à universidade, quanto para auxiliar as/os acadêmicas/os veteranas/os em condições de vulnerabilidade.

Para além das políticas de assistência, a UFMS atuou próximo à comunidade externa e desenvolveu pesquisas científicas com o intuito de contribuir para o combate à pandemia. As ações desenvolvidas na instituição foram compiladas em uma página intitulada, Ações de Enfrentamento a Pandemia (Cf.https://www.ufms.br/category/acoes-de-enfrentamento-a-covid-19/), apresentando informações diversas dos trabalhos, projetos e estratégias realizadas pela instituição. A fim de manter as/os acadêmicas/os informadas/os, intensificou-se os canais digitais de comunicação, criando mais sites com informações sobre a pandemia e divulgando o guia de estudo remoto emergencial.

Mesmo com todas essas medidas elaboradas pela universidade, e levando em consideração o contexto socioeconômico individual, é possível que as políticas de assistência não tenham chegado em determinadas/os estudantes, ou que, embora tenham desenvolvido políticas que fomentassem o acesso ao ensino remoto, ainda assim, a aprendizagem da/o acadêmica/o pode ter sido impactada pelas mudanças emergenciais na educação do país direcionadas pela pandemia, deste modo, faz-se necessário o desenvolvimento de estudos que discorram diretamente sobre o impacto da pandemia na aprendizagem das/os acadêmicas/os, assim como em sua permanência na universidade.

\section{CONCLUSÃO}

A partir das análises aqui estabelecidas, dado o emergente contexto pandêmico, reconhecemos que as IES desenvolveram importantes ações para minimizar as desigualdades geradas pela ausência de aulas presenciais, haja vista que o ensino remoto ainda é pouco explorado na pesquisa em educação, principalmente por ter sido constituído numa situação excepcional, sem prévia regulamentação ou parâmetros de acompanhamento e qualidade. 
A UFMS implementou estratégias para o ERE desde março de 2020, sem interrupções e cancelamento do calendário acadêmico, sendo uma das primeiras instituições da região Centro Oeste a publicar um documento de orientação sobre atividades didáticas remotas, mantendo as atividades acadêmicas de forma remota desde o início da pandemia, o que gerou resistências sobre a adoção dessa forma como estratégia de substituição das aulas presenciais, pois, nas outras IES houve um tempo de preparação e espera de um possível retorno presencial.

As políticas e ações institucionais fomentadas pela UFMS demonstram a preocupação em atender as demandas pelo ensino remoto, todavia, mantém-se o questionamento a respeito da qualidade da educação que tem sido ofertada, uma vez que não basta substituir, por meio de resoluções e decretos, um calendário acadêmico com a matriz curricular planejada para o ensino presencial e sancionar que doravante determinado momento (mesmo que seja emergencialmente), passará a funcionar de modo remoto sem analisar a totalidade de elementos que essas mudanças provocaram na aprendizagem das/dos acadêmicas/os.

Neste aspecto, consideramos alguns questionamentos pertinentes à instituição de pesquisa escolhida considerando que, as ações da UFMS denotam uma preocupação em manter o calendário acadêmico em curso, mesmo no início da pandemia, enquanto outras IES optaram pela suspensão provisória das aulas presenciais. Nesse sentido, elencamos alguns aspectos a serem pesquisados: A educação ofertada por meio do ERE pode ser considerada como de qualidade? As políticas de assistência estudantil têm sido o suficiente para atender as dificuldades acadêmicas? 0 empréstimo dos aparelhos eletrônicos e chips com internet, tem garantido o acesso às aulas remotas? E por fim, como a dificuldade de acesso das/dos estudantes às diferentes plataformas digitais de comunicação utilizadas pela UFMS tem impactado na aprendizagem destas/es? Assim, compreendemos que, embora muitas medidas já tenham sido fomentadas, as políticas educacionais emergenciais promovidas em contexto de pandemia ainda carecem de estudos, reformulações e investimentos por parte do Estado.

\section{REFERÊNCIAS}

BARBOSA, R. J.; SOUZA, P. H.; \& SOARES, S. S. Distribuição de renda nos anos 2010: uma década perdida para desigualdade e pobreza. Rio de Janeiro: Instituto de Pesquisa Econômica Aplicada Ipea, 2020. Disponível em: https://doi.org/10.38116/td2610. Acesso em: 22 out. 2021.

BRASIL. Ministério da Educação. Coronavírus: monitoramento nas instituições de ensino. Brasília, DF: MEC, 2020a. Disponível em: http://portal.mec.gov.br/coronavirus/. Acesso em: 21 out. 2021.

BRASIL. Ministério da Saúde. Informações sobre a Covid-19. Brasília, 2020b.

CASTIONI, Remi et. al. Universidades federais na pandemia da Covid-19: acesso discente à internet e ensino remoto emergencial. Ensaio: Avaliação e Políticas Públicas em Educação, Rio de Janeiro, v. 29, n. 111, p. 399-419, 2021. Disponível em: https://doi.org/10.1590/S010440362021002903108 Acesso em: 22 out. 2021.

IBGE. Pesquisa Nacional por Amostra de Domicílios (PNAD). 2019. Disponível em: https://www.ibge.gov.br/estatisticas/sociais/populacao/17270-pnadcontinua.html?edicao=30362\&t=sobre. Acesso em: 22 out. 2021. 
IBGE. Desemprego. 2021. Disponível em: https://www.ibge.gov.br/explica/desemprego.php. Acesso em: 22 out. 2021.

JUNIOR, Edis. Ações pedagógicas e o uso de tecnologias da UFMS durante a pandemia de COVID19. 2020. Disponível em: https://ppgenfermagemcptl.ufms.br/acoes-pedagogicas-e-o-uso-detecnologias-da-ufms-durante-a-pandemia-de-covid-19/. Acesso em: 18 out. 2021.

LIMA, D.C.B.P.; ALONSO,K.M; ECHALAR, A.D.L.F. Educação a distância no Brasil: COVID-19, desafios emergentes e qualidade da educação. In. Capítulo V. Políticas Educacionais Democráticas em Tempos de Resistência. [Meio Eletrônico]. Brasília, ANPAE, 2021.

MANCEBO, Deise. O golpe de 2016 e os impactos para a educação superior brasileira. Revista Educação em Questão, v. 56, n. 49, p. 62-84, 2018. Disponível em: https://doi.org/10.21680/19811802.2018v56n49ID14477 Acesso em: 22 out. 2021.

PIRES, André. A Covid-19 e a Educação Superior no Brasil: usos diferenciados das tecnologias de comunicação virtual e o enfrentamento das desigualdades educacionais. Educación, v. 30, n. 58, p. 83-103, 2021. Disponível em: https://doi.org/10.18800/educacion.202101.004 Acesso em: 22 out. 2021.

UFMS. Relatório de ações institucionais de enfrentamento à Covid-19 e seus benefícios à sociedade. 2020. disponível em: https://www.ufms.br/wpcontent/uploads/2020/09/Relat\%C3\%B3rio a\%C3\%A7\%C3\%B5es Covid 2020.pdf . Acesso em: 20 out. 2021.

UFMS. Relatório de Acompanhamento de ações durante o ensino remoto de emergência. 2021. Disponível em: https://www.ufms.br/wp-content/uploads/2021/08/Relatorio-deAcompanhamento-de-Acoes-durante-o-Ensino-Remoto-de-Emergencia 1.pdf . Acesso em: 20 out. 2021.

UNESCO. Covid-19: educational disruption and response. Beirut, 2020. Disponível em: https://en.unesco.org/news/covid-19-educationaldisruption-and-response. Acesso em: 22 out. 2021. 